\title{
Surgical management in phyllodes tumors of the breast: a systematic review and meta-analysis
}

\author{
Yufan Wei ${ }^{1,2 \#}$, Yanying Yu ${ }^{3 \#}$, Yashuang $\mathrm{Ji}^{4}$, Yuting Zhong ${ }^{2,5}$, Ningning Min ${ }^{1,2}$, Huayu $\mathrm{Hu}^{1,2}$, \\ Qingyu Guan ${ }^{1,2}$, Xiru Li ${ }^{2}$
}

${ }^{1}$ School of Medicine, Nankai University, Tianjin, China; ${ }^{2}$ Department of General Surgery, The First Medical Center of Chinese PLA General Hospital, Beijing, China; ${ }^{3}$ Eight-Year MD Program, Peking Union Medical College, Chinese Academy of Medical Sciences, Beijing, China; ${ }^{4}$ Department of Galactophore Surgery, Tongzhou District Hospital of Integrated TCM \& Western Medicine, Beijing, China; ${ }^{5}$ Medical School of Chinese PLA, Beijing, China

Contributions: (I) Conception and design: X Li, Y Wei; (II) Administrative support: X Li; (III) Provision of study materials or patients: X Li; (IV) Collection and assembly of data: All authors; (V) Data analysis and interpretation: All authors; (VI) Manuscript writing: All authors; (VII) Final approval of manuscript: All authors.

"These authors contributed equally to this work.

Correspondence to: Xiru Li. Department of General Surgery, The First Medical Center of Chinese PLA General Hospital, Beijing 100853, China. Email: 2468li@sina.com.

Background: Information is still controversial in the studies regarding the current optimal surgical management of phyllodes tumors (PTs) of the breast. Local recurrence (LR) may occur with an upgraded in the pathological grade, influencing the prognosis of patients with PT. This systematic review and metaanalysis aimed to investigate the association of LR risk with margin status and margin width which could have significant implications on the surgical management of PT.

Methods: Independent and comprehensive searches were performed by two authors through five databases including PubMed, Medline, Embase, ScienceDirect and Cochrane Library from January 1990 to October 2021. Studies investigating the association between margin width, margin status and LR rates were considered for inclusion. Study quality was evaluated using the Newcastle-Ottawa Scale (NOS). Metaanalysis was performed using RevMan5.3 software, and statistical heterogeneity was assessed using the Chisquare test and quantified using the $\mathrm{I}^{2}$ statistic. Visual inspection of funnel plots was used to judge publication bias.

Results: A total of 34 articles were included in this article, all of which with NOS scores above 5 . Regardless of the PT grade, positive margin significantly increased the risk of LR [odds ratio (OR) 3.64, 95\% confidence interval (CI): 2.60-5.12]. No significant difference was found in the risk of LR between the margins $<1$ and $\geq 1 \mathrm{~cm}$ (OR 1.39, 95\% CI: 0.67-2.92). For benign and borderline PTs, there were no significant differences of the LR risk between breast-conserving surgery (BCS) and mastectomy (benign OR $0.68,95 \%$ CI: $0.12-3.78$; borderline OR $1.14,95 \%$ CI: 0.29-4.51). While the LR risk was significantly increased by BCS for malignant PT (OR 2.77, 95\% CI: 1.33-5.74).

Discussion: Different surgical management strategies should be considered for different PT grades. BCS was a feasible option and margins $<1 \mathrm{~cm}$ was not significantly associated with LR risk for all grade of PT. After BCS, benign PT with positive margin could adopt the "wait and watch" strategy with regular followup, while borderline and malignant PTs were expected to underwent re-excision to ensure negative margins. More studies are still needed to clarify and update the existing conclusions and improve the prognosis of PT patients.

Keywords: Phyllodes tumors of the breast; surgical management; margin; local recurrence (LR); systematic review and meta-analysis 
Submitted Nov 22, 2021. Accepted for publication Jan 24, 2022.

doi: $10.21037 / g s-21-789$

View this article at: https://dx.doi.org/10.21037/gs-21-789

\section{Introduction}

Phyllodes tumors (PTs) of the breast are uncommon fibroepithelial lesions (FELs), accounting for about $0.3-1 \%$ of breast tumors and $2-3 \%$ of FELs $(1,2)$. This disease was first reported by Johannes Müller in 1838 and called cystosarcoma phyllodes (3). Since then, up to 60 names have been reported such as pseudosarcomatoid adenoma and carcinosarcoma. In 1982, the World Health Organization (WHO) officially named it as PT, and divided it into three grades including benign, borderline and malignant. Studies have shown that LR might occur in every grade with the rate of $10-17 \%, 14-25 \%$ and $23-30 \%$ respectively. Some recurrent cases could also have an upgrading of the pathological grade (4). It is of great significance to achieve effective resection of $\mathrm{PT}$ for reducing the rate of local recurrence (LR) and prolonging the disease-free survival of patients.

Margin width and status are two important factors affecting the prognosis. Previously, National Comprehensive Cancer Network (NCCN) guidelines recommended a margin of at least $1 \mathrm{~cm}$ regardless of tumor grade with many studies supporting, including a meta-analysis conducted by Toussaint et al. (2,5-9). While some studies investigated that for benign PT, no significant difference of LR between $<1$ and $\geq 1 \mathrm{~cm}$ margins was found (10). Thind et al. even indicated that margin $<1 \mathrm{~cm}$ was also acceptable for borderline and malignant PTs (11). As for margin status, some studies suggested that positive margin was significantly related to the increase of LR risk $(12,13)$. However, Lu et al. proposed that margin status was only found to be associated with LR risk for malignant PT (14).

Surgical management of breast-conserving surgery (BCS) and mastectomy is still controversial as the main treatment of PT. Studies have shown that for benign and borderline PT, wide local excision (WLE) can reduce the LR rate from $21-46 \%$ to $8-29 \%(15,16)$. However, some studies indicated that regular follow-up was adequate since the LR rate of benign $\mathrm{PT}$ with positive margin was very low. And re-excision was only suitable for borderline and malignant PTs if safe margin $<1 \mathrm{~cm}(17)$. Recently, a retrospective study of 550 cases by Rosenberger et al. found that ensuring a wider margin had nothing to do with reducing the risk of LR. They proposed that re-excision was not necessary for benign PT to ensure negative margin and suggested a revision of NCCN guidelines (18). In 2021, the fourth edition of NCCN guidelines modified the treatment option of benign PT from WLE to observation after excisional biopsy (19).

The object of this study is to explore the correlation between margin status, margin width, surgical treatment and LR risk for different grade of PT, supposing to contribute to the formulation of surgical method of PT and improve the prognosis of patients. We presented the following article in accordance with the PRISMA reporting checklist (available at https://gs.amegroups.com/article/ view/10.21037/gs-21-789/rc).

\section{Methods}

This study has been registered in the International Prospective Register of Systematic Reviews 'PROSPERO' database (ID: CRD42021292859).

\section{Eligibility criteria}

The literature included in this study contained prospective or retrospective studies of female patients diagnosed pathologically with primary breast PTs. The cases included in the literature should be reviewed by pathologists which clearly report the tumor grade, surgical margins (margin width or margin status), and LR rate. For surgical margins, literature that only reported the surgical process (lumpectomy, WLE, or mastectomy, etc.) without precise definition of margin width and positive or negative criteria for margins should be excluded. If the margin information was only evaluated in patients treated by BCS, then the number of mastectomy cases was subtracted from the total number of cases. If a re-excision was performed, the margin was determined by the information of the last operation. To reduce publication bias, studies only included margin status and with fewer than 50 cases were also excluded. In addition, we only included research articles published in English. All case reports, reviews and comments were excluded. 


\section{Search strategy}

A three steps search strategy was performed in this study. First, we searched the MeSH terms and free terms of PT, surgical margin and LR in PubMed database, and formulated corresponding search strategies according to the search methods of different databases. A full search strategy was detailed in Appendix 1. Then, a comprehensive second search was conducted through the five databases including PubMed, Medline, Embase, ScienceDirect, and Cochrane Library for the articles published between January 1990 and October 2021. Finally, the retrieved studies were screened for follow-up research.

\section{Selection of studies}

All retrieved articles were uploaded for screening with the duplicate studies deleted. Then, two authors conducted independent screening based on the title and abstract of the literature, and initially deleted the literature that did not meet the inclusion criteria. Finally, the full texts were read in detail and the included studies were confirmed. The disagreement between the two authors in the process of selection was resolved through discussion or discussion with the third author.

\section{Assessment of methodological quality}

All the included studies were independently evaluated for methodological quality by two authors using the modified NOS, which mainly included three modules (subject selection, comparability, and exposure/outcome). Scores were assigned in the form of '*'. The final score was among $0-9$ points.

\section{Data extraction}

The two authors independently extracted the data at the same time, and confirmed the final data through comparison and review. The extraction data included the author's name, publication year, the basic information of the included cases (nationality, age, and the total number of cases), the pathological classification of the cases, the surgical treatment, and the follow-up time to form a table of the features of included literature. The margin status, margin width, the surgical treatment and LR of different grades were extracted for subsequent analysis. All the extracted data was input into the Microsoft Excel database.
Funnel plots were drawn to assess the publication bias.

\section{Statistical analysis}

The analyses were performed using Review Manager 5.3 (Cochrane Collaboration, Oxford, UK). The odds ratios (OR) were used to compare dichotomous variables and all results were reported with $95 \%$ confidence intervals (CIs). The random effects model was used to analyze the pooled data. Sensitivity analysis was carried out by deleting a study every time and checking whether the effect size changed. Statistical heterogeneity between studies was assessed using the Chi-square test and quantified using the $\mathrm{I}^{2}$ statistic. A significant statistical difference was considered when $\mathrm{P}<0.05$.

\section{Results}

\section{Literature search results}

A total of 1,089 articles were retrieved in this study with 274 duplicate articles eliminated. By reading the title of the article, searching the full text, and rigorously screening according to the inclusion and exclusion criteria, 34 articles were finally included for subsequent research and analysis. A PRISMA flow diagram summarizing the process of literature selection were presented in Figure 1. All studies included had a quality score of 5 or higher were considered to have good quality (Table S1).

\section{Characteristics of the included studies}

All 34 articles included in this study were retrospective studies, including 6,431 patients from 1944 to 2019 (Table 1). Among them, 3,898 cases were benign, 1,322 were borderline, and 1,221 were malignant. The age of the patients was the median or average age which ranged from 34 to 51 years old. Surgical treatment included BCS and mastectomy, with 4,779 cases and 803 cases respectively. The median follow-up time was between 19.2 and 120 months.

\section{Margin status}

A total of 26 articles evaluated the correlation between surgical margin status (positive or negative) and LR risk. Overall, compared with negative margins, positive margins could significantly increase the risk of LR (OR 3.64; 95\% 
Identification of studies via databases and registers
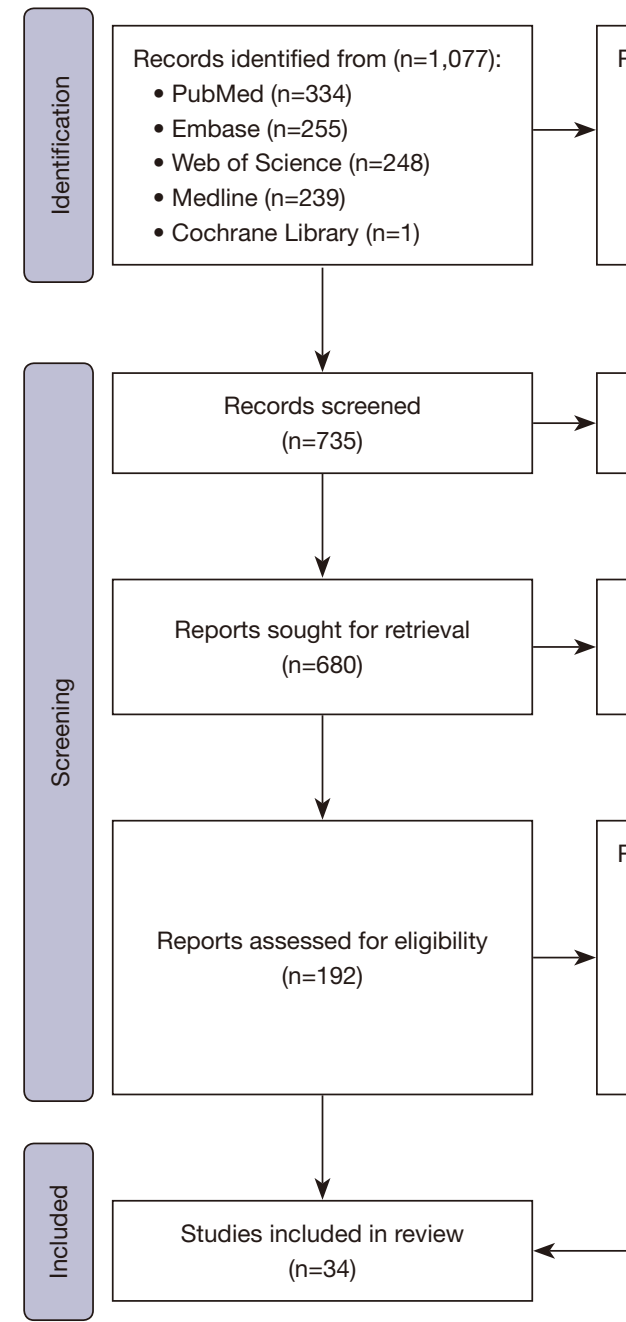

Reports assessed for eligibility $(n=192)$

Studies included in review $(n=34)$ case report $(n=23)$ $(n=93)$
Records removed before screening:

- Duplicate records removed $(n=274)$

- Records marked as ineligible by

automation tools $(n=23)$

- Records removed for other reasons

$(n=45)$
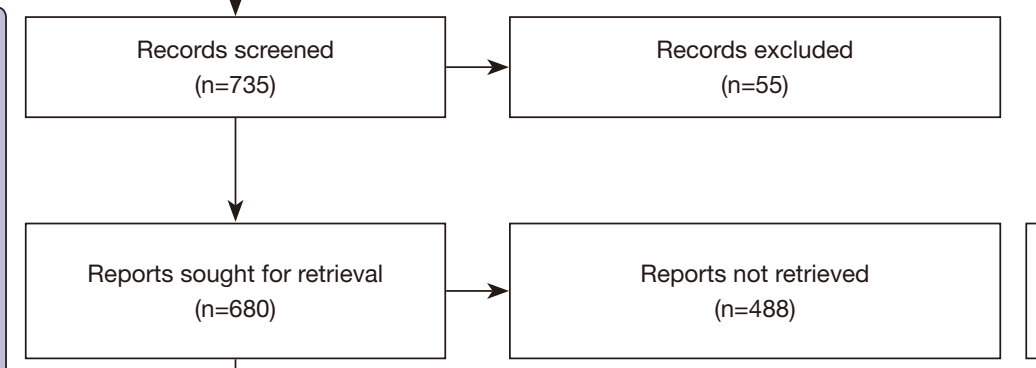

Figure 1 Article retrieval process.

CI: 2.60-5.12) (Figure 2). Ten, eight and eight studies reported LR rates for the benign, borderline and malignant PTs (Figure S1). A positive margin was significantly associated with a high LR risk regardless of tumor grade (benign OR 3.32, 95\% CI: 1.18-9.34; borderline OR 2.88, 95\% CI: $1.16-7.14$ and malignant OR 4.70, 95\% CI: $1.63-$ 13.62).

\section{Margin width}

Most studies still use $1 \mathrm{~cm}$ as the boundary to explore the impact of margin width on the risk of LR. Pooling of data from 14 studies showed no significant difference in the
Identification of studies via other methods
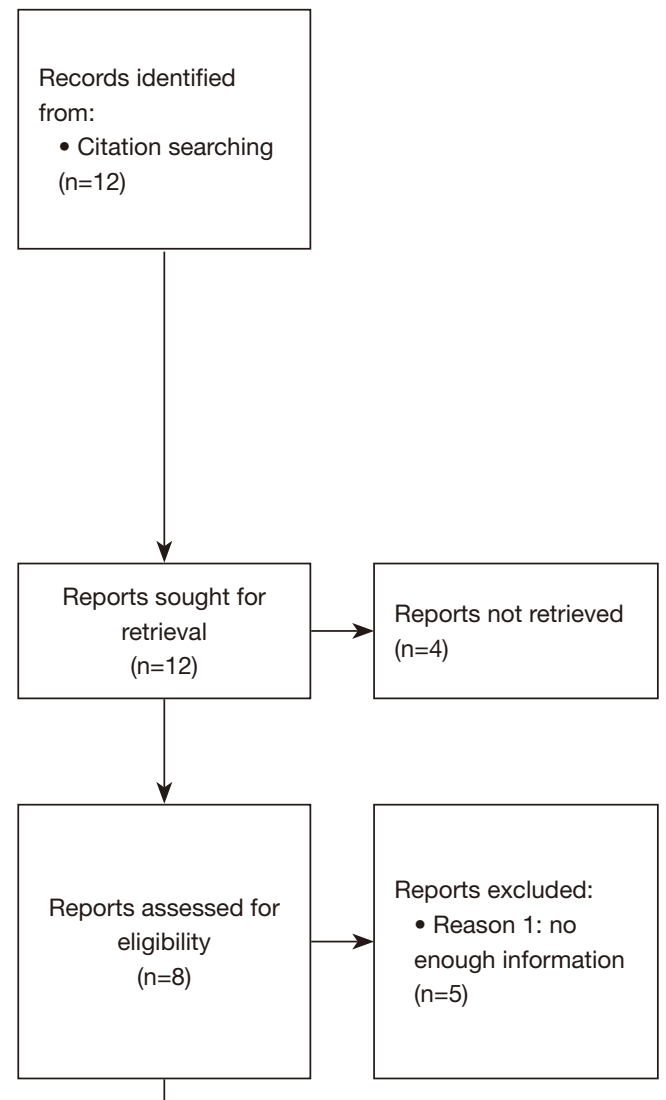

- Reason 4: no enough patients $(n=37)$

Reports excluded:
- Reason 1: no enough information

- Reason 2: not in English $(n=8)$

- Reason 3: review, comments and

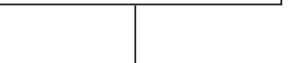

LR risk between patients with margin $\geq 1$ and $<1 \mathrm{~cm}$ (OR 1.39, 95\% CI: 0.67-2.92) (Figure 3). The subgroup analysis included 10 studies for benign, 9 studies for borderline, and 9 studies for malignant PT. The results showed that there was no significant difference in the LR risk between margin width $<1$ and $\geq 1 \mathrm{~cm}$ in all subgroup analysis (benign OR 1.19, 95\% CI: 0.57-2.48; borderline OR 1.37, 95\% CI: $0.42-4.47$ and malignant OR 2.15, 95\% CI: 0.64-7.19) (Figure S2). The borderline and malignant PTs were combined and analyzed with a total of 13 articles included. No significant difference in the LR risk of the margin width between the two groups was found (OR 1.68, 95\% CI: 0.81-3.47) (Figure S3). 
Table 1 Characteristics of the included studies

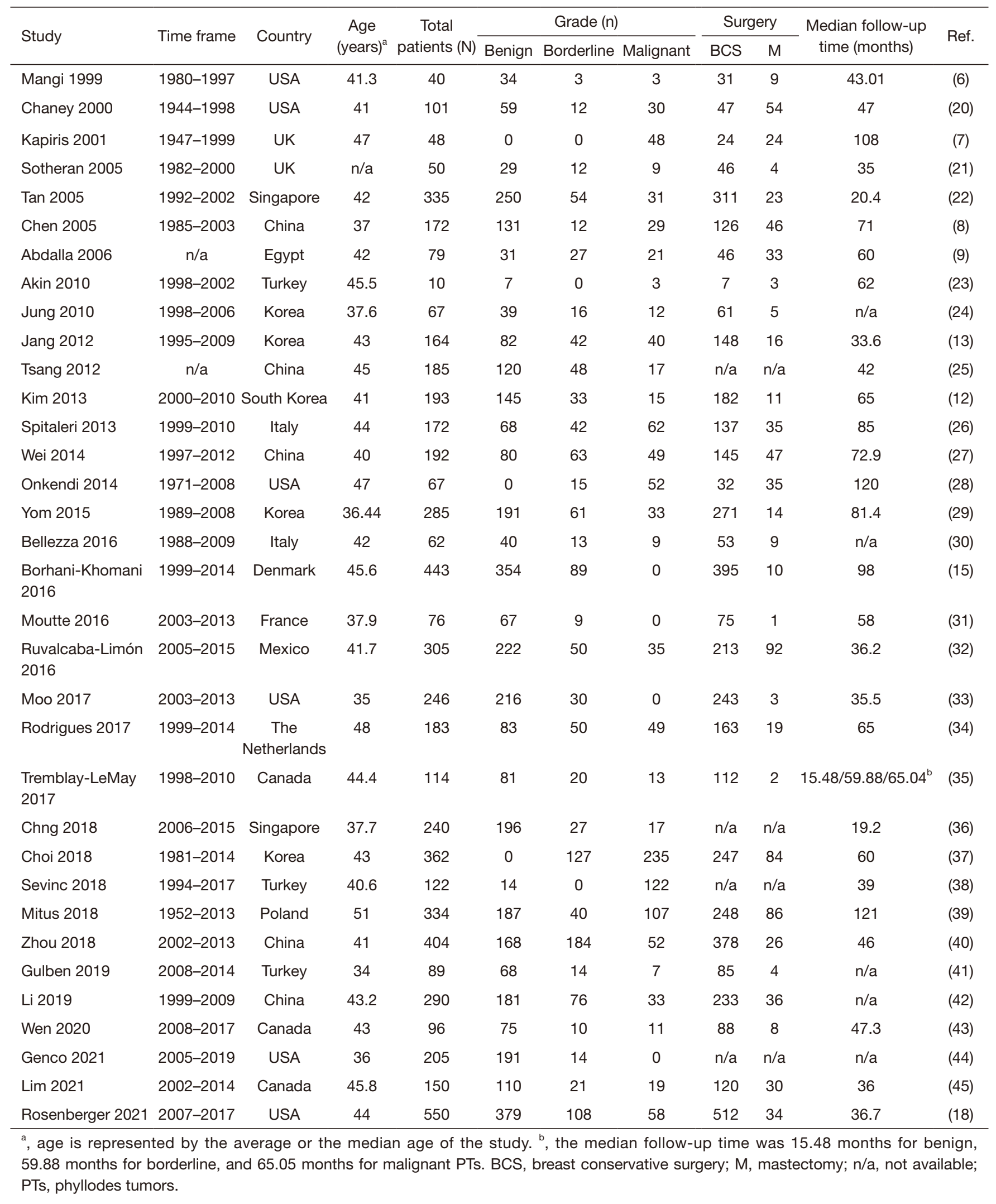




\begin{tabular}{|c|c|c|c|c|c|c|c|c|c|c|c|}
\hline \multirow{2}{*}{ Study or Subgroup } & \multicolumn{2}{|c|}{ Margin Positive } & \multicolumn{2}{|c|}{ Margin Negative } & \multicolumn{3}{|c|}{ Odds Ratio } & \multirow{2}{*}{\multicolumn{4}{|c|}{$\begin{array}{c}\text { Odds Ratio } \\
\text { M-H, Random, } 95 \% \mathrm{Cl}\end{array}$}} \\
\hline & Events & lotal & Events & Total & Weight & M-H, Random, 95\% Cl & Year & & & & \\
\hline Chaney 2000 & 0 & 1 & 4 & 100 & $1.0 \%$ & $7.15[0.25,201.16]$ & 2000 & & & & $\longrightarrow$ \\
\hline Chen 2005 & 6 & 13 & 13 & 159 & $4.9 \%$ & $9.63[2.82,32.91]$ & 2005 & & & & \\
\hline Sotheran 2005 & 5 & 21 & 2 & 24 & $2.9 \%$ & $3.44[0.59,20.02]$ & 2005 & & & & \\
\hline Tan 2005 & 29 & 195 & 14 & 139 & $8.9 \%$ & $1.56[0.79,3.08]$ & 2005 & & & & \\
\hline Jung 2010 & 4 & 4 & 7 & 63 & $1.2 \%$ & $67.80[3.31,1388.47]$ & 2010 & & & & $\rightarrow$ \\
\hline Tsang 2012 & 11 & 30 & 22 & 121 & $7.2 \%$ & $2.61[1.09,6.25]$ & 2012 & & & & \\
\hline Jang 2012 & 8 & 22 & 23 & 139 & $6.5 \%$ & $2.88[1.08,7.66]$ & 2012 & & & & \\
\hline Kim 2013 & 4 & 26 & 14 & 167 & $5.1 \%$ & $1.99[0.60,6.58]$ & 2013 & & & & \\
\hline Spitaleri 2013 & 3 & 10 & 16 & 161 & $3.9 \%$ & $3.88[0.91,16.52]$ & 2013 & & & & \\
\hline Wei 2014 & 3 & 5 & 27 & 187 & $2.7 \%$ & $8.89[1.42,55.69]$ & 2014 & & & & \\
\hline Yom 2015 & 3 & 45 & 15 & 217 & $4.7 \%$ & $0.96[0.27,3.47]$ & 2015 & & & & \\
\hline Bellezza 2016 & 6 & 18 & 6 & 44 & $4.6 \%$ & $3.17[0.86,11.67]$ & 2016 & & & & \\
\hline Moutte 2016 & 2 & 7 & 1 & 65 & $1.6 \%$ & $25.60[1.96,333.55]$ & 2016 & & & & \\
\hline Tremblay-Lemay 2017 & 0 & 2 & 5 & 112 & $1.1 \%$ & $3.91[0.17,91.68]$ & 2017 & & & & \\
\hline Moo 2017 & 0 & 57 & 4 & 159 & $1.2 \%$ & $0.30[0.02,5.67]$ & 2017 & & & & \\
\hline Rodrigues 2017 & 5 & 20 & 11 & 161 & $5.2 \%$ & $4.55[1.39,14.84]$ & 2017 & & & & \\
\hline Zhou 2018 & 1 & 5 & 51 & 347 & $2.0 \%$ & $1.45[0.16,13.24]$ & 2018 & & & & \\
\hline Choi 2018 & 15 & 35 & 37 & 230 & $8.2 \%$ & $3.91[1.84,8.33]$ & 2018 & & & & \\
\hline Sevinc 2018 & 0 & 43 & 0 & 65 & & Not estimable & 2018 & & & & \\
\hline Chng 2018 & 11 & 66 & 2 & 174 & $3.6 \%$ & $17.20[3.70,79.98]$ & 2018 & & & & \\
\hline Gulben 2019 & 7 & 16 & 5 & 73 & $4.4 \%$ & $10.58[2.76,40.47]$ & 2019 & & & & \\
\hline Li 2019 & 11 & 46 & 8 & 162 & $6.4 \%$ & $6.05[2.27,16.15]$ & 2019 & & & & \\
\hline Wen 2020 & 4 & 21 & 3 & 73 & $3.4 \%$ & $5.49[1.12,26.87]$ & 2020 & & & & \\
\hline Genco 2021 & 1 & 21 & 2 & 110 & $1.7 \%$ & $2.70[0.23,31.21]$ & 2021 & & & & \\
\hline Lim 2021 & 3 & 14 & 8 & 136 & $3.9 \%$ & $4.36[1.01,18.84]$ & 2021 & & & & \\
\hline Rosenberger 2021 & 2 & 75 & 13 & 467 & $3.7 \%$ & $0.96[0.21,4.33]$ & 2021 & & & & \\
\hline Total $(95 \% \mathrm{CI})$ & & 818 & & 3855 & $100.0 \%$ & $3.64[2.60,5.12]$ & & & & & \\
\hline Total events & 144 & & 313 & & & & & & & & \\
\hline $\begin{array}{l}\text { Heterogeneity: } \mathrm{Tau}^{2}= \\
\text { Test for overall effect: }\end{array}$ & $\begin{array}{l}2 ; \mathrm{Chi}^{2}= \\
7.47(\mathrm{P}\end{array}$ & $\begin{array}{l}49, \mathrm{df} \\
00001\end{array}$ & $f=24(P=$ & $6) ; 1^{2}$ & $=32 \%$ & & & 0.01 & $\begin{array}{c}0.1 \\
\text { Margin Negative }\end{array}$ & 1 Marigin Posi & 100 \\
\hline
\end{tabular}

Figure 2 Forest plot showing the pooled odds ratios of local recurrence by surgical margin (positive vs. negative).

\begin{tabular}{|c|c|c|c|c|c|c|c|c|c|c|c|}
\hline Study or Subgroup & $\begin{array}{l}\text { Margin } \\
\text { Events }\end{array}$ & $\begin{array}{l}<1 \mathrm{~cm} \\
\text { Total }\end{array}$ & \multicolumn{2}{|c|}{ Margin $\geq 1 \mathrm{~cm}$} & \multicolumn{3}{|c|}{ Odds Ratio } & \multicolumn{4}{|c|}{$\begin{array}{l}\text { Odds Ratio } \\
\text { M-H, Random, } 95 \% \mathrm{Cl}\end{array}$} \\
\hline Mangi 1999 & 5 & 18 & 0 & 22 & $4.9 \%$ & $18.33[0.94,358.30]$ & 1999 & & & & $\longrightarrow$ \\
\hline Kapiris 2001 & 6 & 10 & 4 & 14 & $10.4 \%$ & $3.75[0.67,20.86]$ & 2001 & & & & \\
\hline Chen 2005 & 11 & 71 & 8 & 55 & $16.8 \%$ & $1.08[0.40,2.89]$ & 2005 & & & & \\
\hline Abdalla 2006 & 8 & 22 & 6 & 24 & $14.0 \%$ & $1.71[0.48,6.09]$ & 2006 & & & & \\
\hline Akin 2010 & 0 & 0 & 0 & 10 & & Not estimable & 2010 & & & & \\
\hline Kim 2013 & 7 & 122 & 6 & 36 & $15.0 \%$ & $0.30[0.10,0.97]$ & 2013 & & & & \\
\hline Onkendi 2014 & 2 & 5 & 6 & 27 & $8.7 \%$ & $2.33[0.31,17.35]$ & 2014 & & & & \\
\hline Borhani-Khomani 2016 & 6 & 138 & 1 & 53 & $8.0 \%$ & $2.36[0.28,20.11]$ & 2016 & & & & \\
\hline Ruvalcaba-Limon 2016 & 0 & 0 & 16 & 254 & & Not estimable & 2016 & & & & \\
\hline Choi 2018 & 2 & 9 & 1 & 38 & $6.3 \%$ & $10.57[0.84,133.07]$ & 2018 & & & & $\rightarrow$ \\
\hline Sevinc 2018 & 0 & 54 & 0 & 16 & & Not estimable & 2018 & & & & \\
\hline Li 2019 & 4 & 106 & 1 & 14 & $7.4 \%$ & $0.51[0.05,4.92]$ & 2019 & & & & \\
\hline Mitus 2019 & 1 & 32 & 28 & 302 & $8.5 \%$ & $0.32[0.04,2.40]$ & 2019 & & & & \\
\hline Lim 2021 & 0 & 31 & 0 & 3 & & Not estimable & 2021 & & & & \\
\hline Total $(95 \% \mathrm{Cl})$ & & 618 & & 868 & $100.0 \%$ & $1.39[0.67,2.92]$ & & & & & \\
\hline \multirow{2}{*}{\multicolumn{8}{|c|}{$\begin{array}{l}\text { Heterogeneity: } \mathrm{Tau}^{2}=0.59 ; \mathrm{Chi}^{2}=16.54, \mathrm{df}=9(\mathrm{P}=0.06) ; \mathrm{I}^{2}=46 \% \\
\text { Test for overall effect: } \mathrm{Z}=0.88(\mathrm{P}=0.38)\end{array}$}} & & & & \\
\hline & & & & & & & & 0.01 & $0.1{ }^{1}$ & $\begin{array}{r}10 \\
\text { Margin }<1 \mathrm{~cm}\end{array}$ & 100 \\
\hline
\end{tabular}

Figure 3 Forest plot showing the pooled odds ratios of local recurrence by surgical margin (margin $<1 v s . \geq 1 \mathrm{~cm}$ ).

\section{Surgical treatment}

A total of 15 studies which contained LR rates for different surgical treatments were extracted. Four, five and six studies reported LR rates for the benign, borderline, and malignant PTs respectively (Figure 4). No significant difference between BCS and mastectomy in benign and borderline PT were found (benign OR $0.68,95 \%$ CI: $0.12-3.78$; borderline OR 1.14, 95\% CI: 0.29-4.51). But BCS was significantly associated with a higher LR risk for malignant PT (OR 2.77, 95\% CI: 1.33-5.74). 


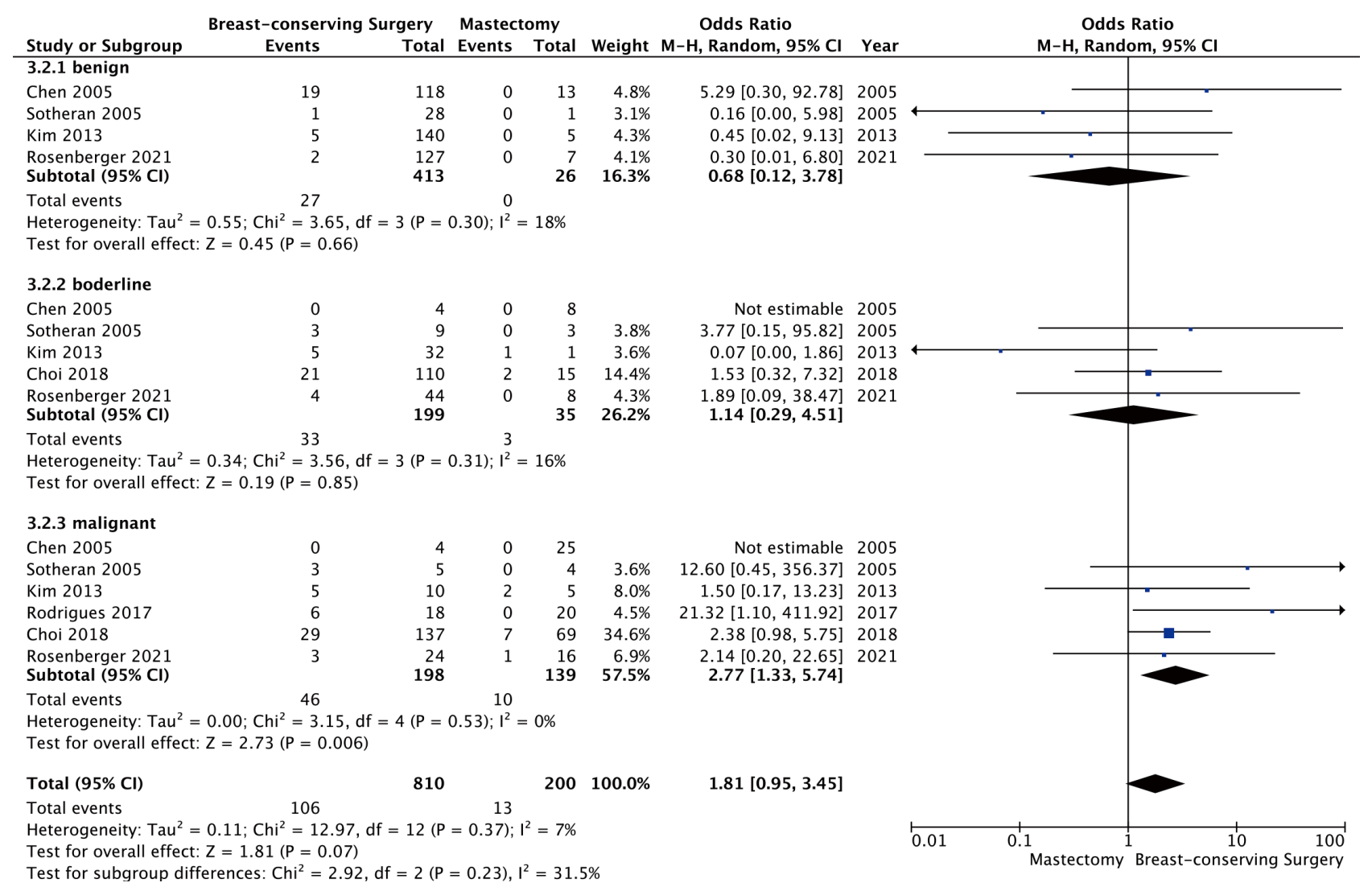

Figure 4 Forest plot showing the pooled odds ratios of local recurrence by surgical treatment (breast-conserving surgery vs. mastectomy) stratified by the phyllodes tumor grade.

\section{Sensitivity analysis and publication bias}

All studies carried out sensitivity analysis and publication bias analysis. Exclusion of Motte et al. or Li et al., as part of the sensitivity analysis, achieved no statistical significance between positive and negative margin for benign PT (Motte exclusion: OR 2.66, 95\% CI: 0.99-7.18; Li exclusion: OR 2.64, 95\% CI: 0.85-8.22). After Li et al. or Wen et al. was excluded, the LR risk achieved no statistically difference between different margin status for borderline PT ( $\mathrm{Li}$ exclusion: OR 2.13, 95\% CI: 0.71-6.43; Wen exclusion: OR 2.43, 95\% CI: 0.96-6.17). The rest of the analysis showed no significant changes in outcomes. No obvious publication bias was observed in the funnel plots (Figures S4,S5). No significant heterogeneity was statistical in this study.

\section{Discussion}

In this systematic review and meta-analysis grounded on a total of 6,431 patients from 34 studies, we assessed the correlation of margin, surgical treatment and LR risk for different grade of PT.

For benign PT, no significant difference in the LR rate between margin $<1$ and $\geq 1 \mathrm{~cm}$ and BCS and mastectomy was found, suggesting that BCS even lumpectomy was adequate for benign PT. As for margin status, we found a significant correlation between positive margin and LR risk, indicating that benign PT with positive margin required re-excision to reduce $L R$ risk. Many studies concluded the same results $(8,26,46,47)$. While some studies suggested that margin status was related to LR only in terms of malignant PT and whether benign PT with positive margins need further resection still required further exploration (14). Shaaban et al. reviewed cases of benign PT and indicated that positive margins increased the LR rate. However, in view of the low LR rate of benign PT with positive resection margin (12.9\%), the strategy of "wait and see" could still be adopted, and re- 
excision is only applicable for borderline and malignant PTs (10). Moo et al. performed a study of 246 benign PT patients with positive margins and found no significant difference in LR between patients underwent re-excision and observation (33). Since the benefits of re-excision on the prognosis of the patient are uncertain and a second operation may bring psychological pressure or cosmetic damage to the patients, "wait and watch" strategy with regular following-up may be an optimal option for benign PT with positive margin.

For borderline PT, we found no significant correlation of LR risk neither with margin width nor surgical treatment, indicating that BCS with a margin less than 1 $\mathrm{cm}$ might be feasible for borderline PT. Ogunbiyi et al. also found that margin $\geq 1$ and $<1 \mathrm{~cm}$ had no significant difference in the LR risk for borderline PT, which was consistent with the result of this study (48). Thind et al. conducted a systematic review and meta-analysis on borderline and malignant PTs, and proposed that the correlation between margin width and LR was not statistically different as well (11). However, there were also studies indicated that borderline PT was resemble to malignant $\mathrm{PT}$ in terms of chromosomal variation and gene mutation and suggested that borderline PT should be given the same attention as malignant PT in making surgical decision $(14,49,50)$. Barth et al. found that $12 / 50$ (24\%) borderline PT locally recurred and indicated BCS with negative margins was not enough for borderline PT to meet a good prognosis (51). Whether the $1 \mathrm{~cm}$ margin is sufficient for borderline PT is still controversial with more cases to supplement.

As for malignant PT, no significant difference in the LR rate between margin $\geq 1$ and $<1 \mathrm{~cm}$ was found which was consistent with the meta-analysis conducted by Thind et al. (11). Some studies also indicated that there was no real advantage to obtain $\geq 1 \mathrm{~cm}$ margins as thinner surgical excisions did not impact LR and the disease-free survival $(13,28,35)$. Neron et al. conducted a multicenter nationwide retrospective study of malignant $\mathrm{PT}$ and suggested that a $3 \mathrm{~mm}$ threshold was sufficient with no impact of wide margins on overall-survival (52). However, the vast majority of studies still recommended WLE with margins $\geq 1 \mathrm{~cm}$ and more studies were needed to identify a precise margin threshold (12,27,53-55). A clearly correlation between positive margin and LR risk was found in terms of margin status. Re-excision was required for malignant PT to obtain negative margin and reduce LR risk $(12,56,57)$. In this study, mastectomy was found having a positive impact on LR risk than BCS which was probably linked to the surgical procedure indicated by Neron et al., that is, en bloc resection along the muscle fascia (52). Mastectomy should be recommended in the situations where the tumor was too large or if the inability to obtain negative margin to reduce $\operatorname{LR}$ risk $(7,58)$.

This study also had some limitations. The studies included were all retrospective studies, and there were only few articles that could be analyzed in the subgroup analysis. Studies are still needed to confirm the reliability of the conclusions. Meanwhile, few studies on $<1$ and $1-10 \mathrm{~mm}$ margins were reported, causing it impossible to evaluate the impact of this threshold on LR risk. In addition, by sensitivity analysis, we found that the correlation between the margin status and LR rate was not statistically significant after the exclusion of some individual studies for benign and borderline PTs. More studies on margin status need to be updated in the future research.

\section{Conclusions}

Different surgical management strategies should be considered for different PT grades. Regardless of the tumor grade, there was a significant correlation between positive margin and LR risk. And BCS was a feasible option as margins $<1 \mathrm{~cm}$ was not significantly associated with LR risk. After BCS, "wait and watch" strategy was adequate for benign PT with positive margin, while borderline and malignant PTs were expected to underwent re-excision to ensure negative margins. Mastectomy was recommended in the situations where the tumor was too large or if the inability to obtain negative margin to reduce LR risk. At present, more retrospective or prospective studies are still needed to clarify and update the existing conclusions and improve the prognosis of $\mathrm{PT}$ patients.

\section{Acknowledgments}

Funding: None.

\section{Footnote}

Reporting Checklist: The authors have completed the PRISMA reporting checklist. Available at https:// gs.amegroups.com/article/view/10.21037/gs-21-789/rc

Peer Review File: Available at https://gs.amegroups.com/ article/view/10.21037/gs-21-789/prf 
Conflicts of Interest: All authors have completed the ICMJE uniform disclosure form (available at https://gs.amegroups. com/article/view/10.21037/gs-21-789/coif). XL serves as an Editor-in-Chief of Gland Surgery from May 2012 to April 2022. The other authors have no conflicts of interest to declare.

Ethical Statement: The authors are accountable for all aspects of the work in ensuring that questions related to the accuracy or integrity of any part of the work are appropriately investigated and resolved.

Open Access Statement: This is an Open Access article distributed in accordance with the Creative Commons Attribution-NonCommercial-NoDerivs 4.0 International License (CC BY-NC-ND 4.0), which permits the noncommercial replication and distribution of the article with the strict proviso that no changes or edits are made and the original work is properly cited (including links to both the formal publication through the relevant DOI and the license). See: https://creativecommons.org/licenses/by-nc-nd/4.0/.

\section{References}

1. Zhang Y, Kleer CG. Phyllodes Tumor of the Breast: Histopathologic Features, Differential Diagnosis, and Molecular/Genetic Updates. Arch Pathol Lab Med 2016;140:665-71.

2. Toussaint A, Piaget-Rossel R, Stormacq C, et al. Width of margins in phyllodes tumors of the breast: the controversy drags on?-a systematic review and meta-analysis. Breast Cancer Res Treat 2021;185:21-37.

3. J. M. Uber den feineren Ban und Die Formen der Krankaften Geschwulste. Germany: Greiner 1838:54-7.

4. Lakhani S, Ellis I, Schnitt S, et al. World Health Organization Classification of Tumours, Volume 2: Breast Tumours (ed 5). Lyon, France, IARC Press. 2019. Available online: https://www.iarc.who.int/news-events/ who-classification-of-tumours-5 th-edition-volume-2breast-tumours/

5. Gradishar WJ, Anderson BO, Abraham J, et al. Breast Cancer, Version 3.2020, NCCN Clinical Practice Guidelines in Oncology. J Natl Compr Canc Netw 2020;18:452-78.

6. Mangi AA, Smith BL, Gadd MA, et al. Surgical management of phyllodes tumors. Arch Surg 1999;134:487-92; discussion 492-3.

7. Kapiris I, Nasiri N, A'Hern R, et al. Outcome and predictive factors of local recurrence and distant metastases following primary surgical treatment of high-grade malignant phyllodes tumours of the breast. Eur J Surg Oncol 2001;27:723-30.

8. Chen WH, Cheng SP, Tzen CY, et al. Surgical treatment of phyllodes tumors of the breast: retrospective review of 172 cases. J Surg Oncol 2005;91:185-94.

9. Abdalla HM, Sakr MA. Predictive factors of local recurrence and survival following primary surgical treatment of phyllodes tumors of the breast. J Egypt Natl Canc Inst 2006;18:125-33.

10. Shaaban M, Barthelmes L. Benign phyllodes tumours of the breast: (Over) treatment of margins - A literature review. Eur J Surg Oncol 2017;43:1186-90.

11. Thind A, Patel B, Thind K, et al. Surgical margins for borderline and malignant phyllodes tumours. Ann R Coll Surg Engl 2020;102:165-73.

12. Kim S, Kim JY, Kim DH, et al. Analysis of phyllodes tumor recurrence according to the histologic grade. Breast Cancer Res Treat 2013;141:353-63.

13. Jang JH, Choi MY, Lee SK, et al. Clinicopathologic risk factors for the local recurrence of phyllodes tumors of the breast. Ann Surg Oncol 2012;19:2612-7.

14. Lu Y, Chen Y, Zhu L, et al. Local Recurrence of Benign, Borderline, and Malignant Phyllodes Tumors of the Breast: A Systematic Review and Meta-analysis. Ann Surg Oncol 2019;26:1263-75.

15. Borhani-Khomani K, Talman ML, Kroman N, et al. Risk of Local Recurrence of Benign and Borderline Phyllodes Tumors: A Danish Population-Based Retrospective Study. Ann Surg Oncol 2016;23:1543-8.

16. Barth RJ Jr. Histologic features predict local recurrence after breast conserving therapy of phyllodes tumors. Breast Cancer Res Treat 1999;57:291-5.

17. Chen K, Chen Y, Cartwright P, et al. Optimizing Surgical Treatment for Phyllodes Tumor. Curr Breast Cancer Rep 2018;10:55-61.

18. Rosenberger LH, Thomas SM, Nimbkar SN, et al. Contemporary Multi-Institutional Cohort of 550 Cases of Phyllodes Tumors (2007-2017) Demonstrates a Need for More Individualized Margin Guidelines. J Clin Oncol 2021;39:178-89.

19. Gradishar WJ, Moran MS, Abraham J, et al. Breast Cancer, Version 4.2021, NCCN Clinical Practice Guidelines in Oncology. J Natl Compr Canc Netw 2021.

20. Chaney AW, Pollack A, McNeese MD, et al. Primary treatment of cystosarcoma phyllodes of the breast. Cancer 2000;89:1502-11. 
21. Sotheran W, Domjan J, Jeffrey M, et al. Phyllodes tumours of the breast--a retrospective study from 19822000 of 50 cases in Portsmouth. Ann R Coll Surg Engl 2005;87:339-44.

22. Tan PH, Jayabaskar T, Chuah KL, et al. Phyllodes tumors of the breast: the role of pathologic parameters. Am J Clin Pathol 2005;123:529-40.

23. Akin M, Irkorucu O, Koksal H, et al. Phyllodes tumor of the breast; a case series. Bratisl Lek Listy 2010;111:271-4.

24. Jung CW, Suh KS, Lee J, et al. Mutation-Free Expression of c-Kit and PDGFRA in Phyllodes Tumors of the Breast. J Breast Cancer 2010;13:257.

25. Tsang JY, Mendoza P, Putti TC, et al. E-cadherin expression in the epithelial components of mammary phyllodes tumors. Hum Pathol 2012;43:2117-23.

26. Spitaleri G, Toesca A, Botteri E, et al. Breast phyllodes tumor: a review of literature and a single center retrospective series analysis. Crit Rev Oncol Hematol 2013;88:427-36.

27. Wei J, Tan YT, Cai YC, et al. Predictive factors for the local recurrence and distant metastasis of phyllodes tumors of the breast: a retrospective analysis of 192 cases at a single center. Chin J Cancer 2014;33:492-500.

28. Onkendi EO, Jimenez RE, Spears GM, et al. Surgical treatment of borderline and malignant phyllodes tumors: the effect of the extent of resection and tumor characteristics on patient outcome. Ann Surg Oncol 2014;21:3304-9.

29. Yom CK, Han W, Kim SW, et al. Reappraisal of conventional risk stratification for local recurrence based on clinical outcomes in 285 resected phyllodes tumors of the breast. Ann Surg Oncol 2015;22:2912-8.

30. Bellezza G, Prosperi E, Del Sordo R, et al. IMP3 Is Strongly Expressed in Malignant Phyllodes Tumors of the Breast: An Immunohistochemical Study. Int J Surg Pathol 2016;24:37-42.

31. Moutte A, Chopin N, Faure C, et al. Surgical Management of Benign and Borderline Phyllodes Tumors of the Breast. Breast J 2016;22:547-52.

32. Ruvalcaba-Limón E, Jiménez-López J, Bautista-Piña V, et al. Phyllodes Tumor of the Breast: 307 Treated Cases, the Largest Mexican Experience at a Single Breast Disease Institution. Iran J Pathol 2016;11:399-408.

33. Moo TA, Alabdulkareem H, Tam A, et al. Association Between Recurrence and Re-Excision for Close and Positive Margins Versus Observation in Patients with Benign Phyllodes Tumors. Ann Surg Oncol 2017;24:3088-92.
34. Rodrigues MF, Truong PT, Weir LM, et al. Phyllodes tumours of the breast: The British Columbia cancer agency experience. Cancer Research 2017;77.

35. Tremblay-LeMay R, Hogue JC, Provencher L, et al. How Wide Should Margins Be for Phyllodes Tumors of the Breast? Breast J 2017;23:315-22.

36. Chng TW, Gudi M, Lim SH, et al. Validation of the Singapore nomogram for outcome prediction in breast phyllodes tumours in a large patient cohort. J Clin Pathol 2018;71:125-8.

37. Choi N, Kim K, Shin KH, et al. Malignant and borderline phyllodes tumors of the breast: a multicenter study of 362 patients (KROG 16-08). Breast Cancer Res Treat 2018;171:335-44.

38. Sevinç Aİ, Aksoy SÖ, Güray Durak M, et al. Is the extent of surgical resection important in patient outcome in benign and borderline phyllodes tumors of the breast? Turk J Med Sci 2018;48:28-33.

39. Mitus JW, Blecharz P, Jakubowicz J, et al. Phyllodes tumors of the breast. The treatment results for 340 patients from a single cancer centre. Breast 2019;43:85-90.

40. Zhou Z, Wang CC, Sun XJ, et al. Prognostic Factors and Local Recurrence Pattern in Breast Phyllodes Tumors: A Nomogram Based on Retrospective Cohort Study of 404 Cases. Int J Radiat Oncol Biol Phys 2018;99:E60-1.

41. Gulben K, Öndeş B, Berberoglu U. Factors Affecting Local Recurrence for Phyllodes Tumors of the Breast: a Retrospective Analysis of 89 Patients in a Single Center. Indian Journal of Surgery 2019. Available online: https://www.semanticscholar.org/paper/ Factors-Affecting-Local-Recurrence-for-Phyllodes-ofG\%C3\%BClben-\%C3\%96nde\%C5\%9F/468e0f5d925c d58bcf2f807b7998568c00b3c3e3

42. Li J, Tsang JY, Chen C, et al. Predicting Outcome in Mammary Phyllodes Tumors: Relevance of Clinicopathological Features. Ann Surg Oncol 2019;26:2747-58.

43. Wen B, Mousadoust D, Warburton R, et al. Phyllodes tumours of the breast: Outcomes and recurrence after excision. Am J Surg 2020;219:790-4.

44. Genco IS, Purohit V, Hackman K, et al. Benign and borderline phyllodes tumors of the breast: Clinicopathologic analysis of 205 cases with emphasis on the surgical margin status and local recurrence rate. Ann Diagn Pathol 2021;51:151708.

45. Lim RS, Cordeiro E, Lau J, et al. Phyllodes Tumors-The Predictors and Detection of Recurrence. Can Assoc Radiol J 2021;72:251-7. 
46. Ben Hassouna J, Damak T, Gamoudi A, et al. Phyllodes tumors of the breast: a case series of 106 patients. Am J Surg 2006;192:141-7.

47. Spanheimer PM, Murray MP, Zabor EC, et al. LongTerm Outcomes After Surgical Treatment of Malignant/ Borderline Phyllodes Tumors of the Breast. Ann Surg Oncol 2019;26:2136-43.

48. Ogunbiyi S, Perry A, Jakate K, et al. Phyllodes tumour of the breast and margins: How much is enough Can J Surg 2019;62:E19-21.

49. Tan J, Ong CK, Lim WK, et al. Genomic landscapes of breast fibroepithelial tumors. Nat Genet 2015;47:1341-5.

50. Laé M, La Rosa P, Mandel J, et al. Whole-genome profiling helps to classify phyllodes tumours of the breast. J Clin Pathol 2016;69:1081-7.

51. Barth JR Jr. Margin negative, breast conserving resection: adequate for benign phyllodes tumors, but inadequate therapy for borderline and malignant phyllodes tumors. Breast Cancer Res Treat 2013;142:463-4.

52. Neron M, Sajous C, Thezenas S, et al. Surgical Margins and Adjuvant Therapies in Malignant Phyllodes Tumors of the Breast: A Multicenter Retrospective Study. Ann Surg

Cite this article as: Wei Y, Yu Y, Ji Y, Zhong Y, Min N, Hu H, Guan Q, Li X. Surgical management in phyllodes tumors of the breast: a systematic review and meta-analysis. Gland Surg 2022;11(3):513-523. doi: 10.21037/gs-21-789
Oncol 2020;27:1818-27.

53. Narayanakar RP, Gangaiah DM, Althaf S, et al. Cystosarcoma phyllodes: Pathological enigma: A retrospective review of 162 cases. Indian J Cancer 2015;52:365-8.

54. Mituś J, Reinfuss M, Mituś JW, et al. Malignant phyllodes tumor of the breast: treatment and prognosis. Breast J 2014;20:639-44.

55. Ramakant P, Chakravarthy S, Cherian JA, et al. Challenges in management of phyllodes tumors of the breast: a retrospective analysis of 150 patients. Indian J Cancer 2013;50:345-8.

56. Tan PH, Thike AA, Tan WJ, et al. Predicting clinical behaviour of breast phyllodes tumours: a nomogram based on histological criteria and surgical margins. J Clin Pathol 2012;65:69-76.

57. Barrio AV, Clark BD, Goldberg JI, et al. Clinicopathologic features and long-term outcomes of 293 phyllodes tumors of the breast. Ann Surg Oncol 2007;14:2961-70.

58. Papas Y, Asmar AE, Ghandour F, et al. Malignant phyllodes tumors of the breast: A comprehensive literature review. Breast J 2020;26:240-4. 


\section{Supplementary}

Appendix 1 Search strategies of this study in different databases

Pubmed

\begin{tabular}{|c|c|}
\hline Search step & Search terms \\
\hline \#2 & $\begin{array}{l}\text { ("Surgical Procedures, Operative" [Mesh] OR "surgical management" [tiab] OR "surgical excision" [tiab] OR "surgical } \\
\text { margin*” OR "margin”" OR "margin”" [tiab] OR "margins assessment") }\end{array}$ \\
\hline \#3 & ("Recurrence" [Mesh] OR "recurrence*" [tiab] OR “Neoplasm Recurrence, Local” [Mesh] OR "relapse*” [tiab]) \\
\hline \#4 & \#1 AND \#2 AND \#3 \\
\hline \multicolumn{2}{|l|}{ Medline } \\
\hline Search step & Search terms \\
\hline$\# 1$ & Phyllodes Tumor or phyllode tumor \\
\hline \#2 & $\begin{array}{l}\text { Surgical Procedures or surgical management or surgical excision or margins assessment or surgical margin* or } \\
\text { margin* }\end{array}$ \\
\hline
\end{tabular}

Web of Science

\begin{tabular}{|c|c|}
\hline Search step & Search terms \\
\hline$\# 1$ & TS= ("Phyllodes Tumor" OR "Phyllodes Tumors" OR "phyllodes tumor" OR "phyllode tumor") \\
\hline \#2 & $\begin{array}{l}\text { TS= ("surgical margin" OR "surgical margins" OR "margin" OR "margins" OR "Surgical Procedure" OR "surgical } \\
\text { management" OR "margins assessment" OR "surgical excision" OR "surgical ablation") }\end{array}$ \\
\hline \#3 & TS= ("Recurrence" OR "Neoplasm Recurrence" OR "relapse" OR "tumor recurrence") \\
\hline \#4 & \#1 AND \#2 AND \#3- (limits: Articles and all years) \\
\hline \multicolumn{2}{|l|}{ EMBASE } \\
\hline Search step & Search terms \\
\hline$\# 1$ & ('phyllodes tumor'/exp OR 'phyllodes tumor' OR 'phyllode tumor') \\
\hline \#2 & $\begin{array}{l}\text { ('surgical margin'/exp OR 'surgical margin' OR 'surgery'/de OR 'surgical management' OR 'margin assessment' OR } \\
\text { 'surgical ablation'/exp OR 'surgical excision') }\end{array}$ \\
\hline
\end{tabular}

Cochrane Library database

\begin{tabular}{ll}
\hline Search step & Search terms \\
\hline$\# 1$ & ("Phyllodes Tumor" OR "Phyllodes Tumors" OR "phyllodes tumor" OR "phyllode tumor") \\
$\# 2$ & ("surgical margin" OR "surgical margins" OR "margin" OR "margins" OR "Surgical Procedure" OR "surgical \\
& management" OR "margins assessment" OR "surgical excision" OR "surgical ablation") \\
$\# 3$ & ("Recurrence" OR "Neoplasm Recurrence" OR "relapse" OR "tumor recurrence") \\
$\# 4$ & $\# 1$ AND \#2 AND \#3 \\
\hline
\end{tabular}


Table S1 Newcastle-Ottawa scale (modified for cohort studies) for assessment of quality of included studies

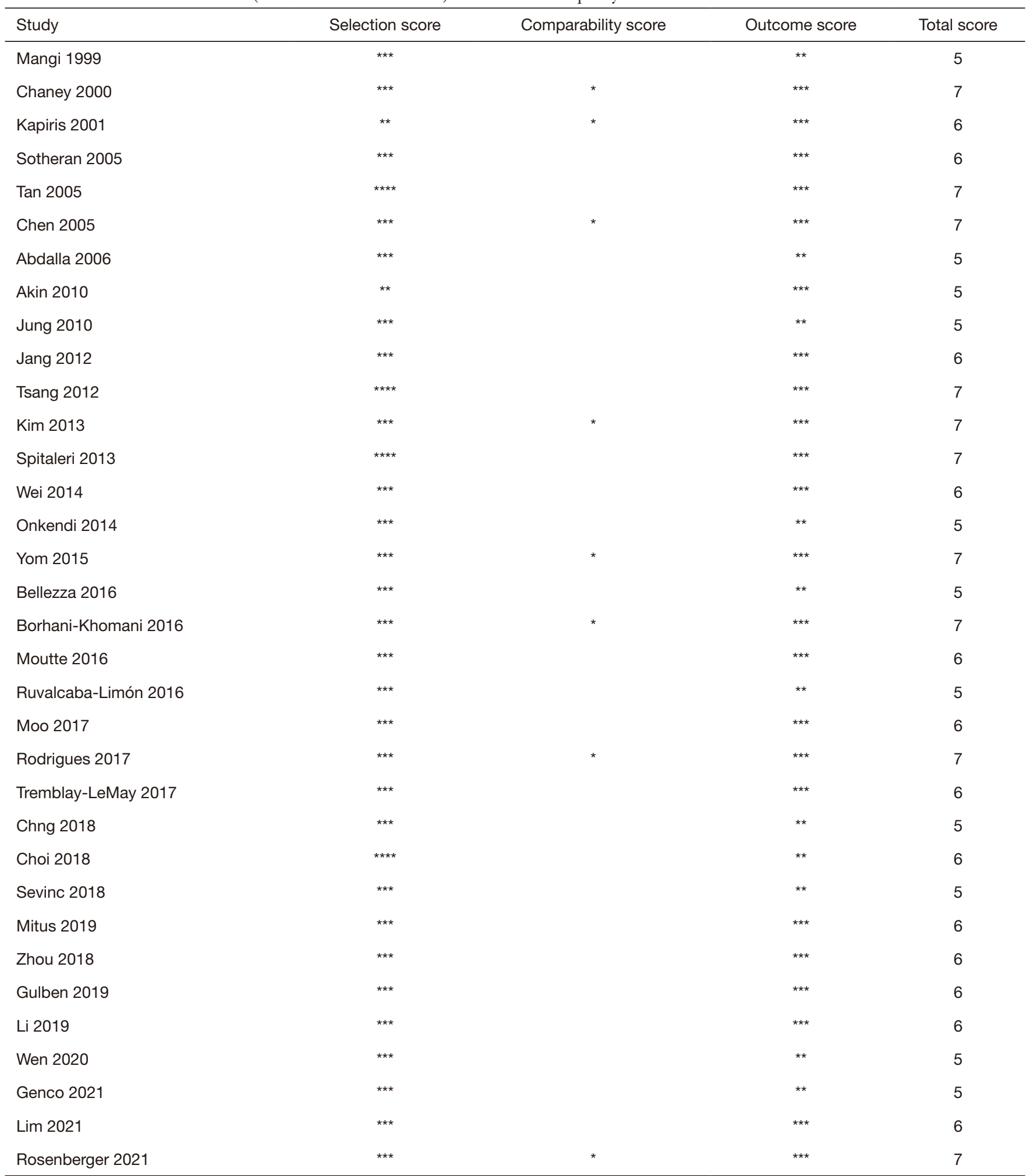

The asterisk $\left(^{*}\right)$ denotes the fulfilment of each criterion according to the Newcastle-Ottawa scale. 


\begin{tabular}{|c|c|c|c|c|c|c|c|c|c|c|}
\hline \multirow{2}{*}{$\begin{array}{l}\text { Study or Subgroup } \\
1.1 .1 \text { Benign }\end{array}$} & \multicolumn{2}{|c|}{ Margin Positive } & \multicolumn{2}{|c|}{ Margin Negative } & \multicolumn{3}{|c|}{ Odds Ratio } & \multicolumn{3}{|c|}{$\begin{array}{c}\text { Odds Ratio } \\
\mathrm{M}-\mathrm{H}, \text { Random, } 95 \% \mathrm{CI}\end{array}$} \\
\hline & & & & & & & & & & \\
\hline Sotheran 2005 & 0 & 12 & 1 & 14 & $2.5 \%$ & $0.36[0.01,9.68]$ & 2005 & & & \\
\hline Spitaleri 2013 & 1 & 1 & 2 & 67 & $2.3 \%$ & $78.60[2.52,2453.26]$ & 2013 & & & \\
\hline Kim 2013 & 1 & 19 & 4 & 126 & $5.2 \%$ & $1.69[0.18,16.02]$ & 2013 & & & \\
\hline Moutte 2016 & 2 & 6 & 0 & 58 & $2.7 \%$ & $65.00[2.69,1569.54]$ & 2016 & & & \\
\hline Moo 2017 & 0 & 57 & 4 & 159 & $3.1 \%$ & $0.30[0.02,5.67]$ & 2017 & & & \\
\hline Tremblay-Lemay 2017 & 0 & 1 & 3 & 80 & $2.4 \%$ & $7.38[0.25,215.72]$ & 2017 & & & \\
\hline Li 2019 & 7 & 31 & 3 & 103 & $11.7 \%$ & $9.72[2.34,40.38]$ & 2019 & & & \\
\hline Wen 2020 & 1 & 18 & 2 & 55 & $4.4 \%$ & $1.56[0.13,18.28]$ & 2020 & & & \\
\hline Lim 2021 & 1 & 12 & 4 & 98 & $5.1 \%$ & $2.14[0.22,20.86]$ & 2021 & & & \\
\hline $\begin{array}{l}\text { Rosenberger } 2021 \\
\text { Subtotal }(95 \% \mathrm{Cl})\end{array}$ & 1 & $\begin{array}{r}60 \\
217\end{array}$ & 4 & $\begin{array}{r}316 \\
1076\end{array}$ & $\begin{array}{r}5.4 \% \\
44.8 \%\end{array}$ & $\begin{array}{r}1.32[0.15,12.04] \\
3.32[1.18,9.34]\end{array}$ & 2021 & & & \\
\hline \multirow{2}{*}{\multicolumn{11}{|c|}{$\begin{array}{l}\text { Heterogeneity: } \text { Tau }^{2}=1.07 ; \mathrm{Chi}^{2}=15.09, \mathrm{df}=9(P=0.09) ; I^{2}=40 \% \\
\text { Test for overall effect: } Z=2.27(P=0.02)\end{array}$}} \\
\hline & & & & & & & & & & \\
\hline \multicolumn{11}{|l|}{ 1.1.2 Borderline } \\
\hline Sotheran 2005 & 2 & 6 & 1 & 6 & $3.6 \%$ & $2.50[0.16,38.60]$ & 2005 & & & \\
\hline Kim 2013 & 1 & 5 & 5 & 28 & $4.6 \%$ & $1.15[0.10,12.62]$ & 2013 & & & \\
\hline Spitaleri 2013 & 0 & 2 & 5 & 39 & $2.7 \%$ & $1.25[0.05,29.78]$ & 2013 & & & \\
\hline Moutte 2016 & 0 & 1 & 1 & 7 & $2.1 \%$ & $1.44[0.04,56.14]$ & 2016 & & & \\
\hline Tremblay-Lemay 2017 & 0 & 1 & 2 & 19 & $2.3 \%$ & $2.33[0.07,74.54]$ & 2017 & & & \\
\hline Li 2019 & 4 & 11 & 4 & 42 & $9.6 \%$ & $5.43[1.09,26.98]$ & 2019 & & & \\
\hline Wen 2020 & 2 & 2 & 0 & 8 & $1.6 \%$ & $85.00[1.32,5478.06]$ & 2020 & & & \\
\hline $\begin{array}{l}\text { Rosenberger } 2021 \\
\text { Subtotal }(95 \% \mathrm{Cl})\end{array}$ & 1 & $\begin{array}{l}12 \\
40\end{array}$ & 5 & $\begin{array}{r}96 \\
245\end{array}$ & $\begin{array}{r}5.3 \% \\
31.7 \%\end{array}$ & $\begin{array}{r}1.65[0.18,15.48] \\
\mathbf{2 . 8 8}[\mathbf{1 . 1 6}, \mathbf{7 . 1 4}]\end{array}$ & 2021 & & & \\
\hline \multirow{2}{*}{\multicolumn{11}{|c|}{$\begin{array}{l}\text { Heterogeneity: } \mathrm{Tau}^{2}=0.00 ; \mathrm{Chi}^{2}=4.37, \mathrm{df}=7(\mathrm{P}=0.74) ; \mathrm{I}^{2}=0 \% \\
\text { Test for overall effect: } Z=2.28(\mathrm{P}=0.02)\end{array}$}} \\
\hline & & & & & & & & & & \\
\hline \multicolumn{11}{|l|}{ 1.1.3 Malignant } \\
\hline Sotheran 2005 & 3 & 3 & 0 & 6 & $1.6 \%$ & $91.00[1.46,5656.47]$ & 2005 & & & \\
\hline Kim 2013 & 2 & 2 & 5 & 13 & $2.6 \%$ & $7.73[0.31,193.44]$ & 2013 & & & \\
\hline Spitaleri 2013 & 2 & 7 & 9 & 55 & $7.9 \%$ & $2.04[0.34,12.23]$ & 2013 & & & \\
\hline Rodrigues 2017 & 2 & 3 & 5 & 45 & $4.0 \%$ & $16.00[1.22,209.93]$ & 2017 & & & \\
\hline Tremblay-Lemay 2017 & 0 & 0 & 0 & 13 & & Not estimable & 2017 & & & \\
\hline Li 2019 & 0 & 4 & 1 & 13 & $2.4 \%$ & $0.93[0.03,27.12]$ & 2019 & & & \\
\hline Wen 2020 & 1 & 1 & 1 & 10 & $2.1 \%$ & $19.00[0.50,719.74]$ & 2020 & & - & \\
\hline $\begin{array}{l}\text { Rosenberger } 2021 \\
\text { Subtotal }(95 \% \mathrm{Cl})\end{array}$ & 0 & $\begin{array}{r}3 \\
23\end{array}$ & 4 & $\begin{array}{r}55 \\
210\end{array}$ & $\begin{array}{r}2.8 \% \\
23.5 \%\end{array}$ & $\begin{array}{l}1.63[0.07,36.87] \\
4.70[1.63,13.62]\end{array}$ & 2021 & & & \\
\hline \multirow{2}{*}{\multicolumn{11}{|c|}{$\begin{array}{l}\text { Total events } \quad 10 \\
\text { Heterogeneity: } \text { Tau }^{2}=0.00 ; \mathrm{Chi}^{2}=5.68, \mathrm{df}=6(\mathrm{P}=0.46) ; \mathrm{I}^{2}=0 \% \\
\text { Test for overall effect: } \mathrm{Z}=2.86(\mathrm{P}=0.004)\end{array}$}} \\
\hline & & & & & & & & & & \\
\hline Total $(95 \% \mathrm{Cl})$ & & 280 & & 1531 & $100.0 \%$ & $3.54[2.08,6.03]$ & & & & \\
\hline Total events & 34 & & 75 & & & & & & & \\
\hline \multicolumn{8}{|c|}{$\begin{array}{l}\text { Heterogeneity: } \mathrm{Tau}^{2}=0.10 ; \mathrm{Chi}^{2}=25.37, \mathrm{df}=24(\mathrm{P}=0.39) ; \mathrm{I}^{2}=5 \% \\
\text { Test for overall effect: } \mathrm{Z}=4.66(\mathrm{P}<0.00001) \\
\text { Test for subgroup differences: } \mathrm{Chi}^{2}=0.48, \mathrm{df}=2(\mathrm{P}=0.78), \mathrm{I}^{2}=0 \%\end{array}$} & 0.002 & $\operatorname{Margin~Negative~}^{1}$ & 10 \\
\hline
\end{tabular}

Figure S1 Forest plot showing the pooled odds ratios of local recurrence by surgical margin (positive vs. negative) stratified by the phyllodes tumor grade. 


\begin{tabular}{|c|c|c|c|c|c|c|c|c|c|c|c|}
\hline Study or Subgroup & $\begin{array}{l}\text { Margin } \\
\text { Events }\end{array}$ & Total & \multicolumn{2}{|c|}{ Margin $\geq 1 \mathrm{~cm}$} & \multicolumn{3}{|c|}{ Odds Ratio } & \multicolumn{4}{|c|}{$\begin{array}{l}\text { Odds Ratio } \\
\text { M-H, Random, } 95 \% \mathrm{Cl}\end{array}$} \\
\hline Mangi 1999 & 1 & 2 & 0 & 4 & $3.9 \%$ & $9.00[0.22,362.48]$ & 1999 & & & & \\
\hline Kapiris 2001 & 6 & 10 & 4 & 14 & $17.9 \%$ & $3.75[0.67,20.86]$ & 2001 & & & & \\
\hline Chen 2005 & 0 & 2 & 0 & 6 & & Not estimable & 2005 & & & & \\
\hline Abdalla 2006 & 5 & 8 & 6 & 16 & $17.2 \%$ & $2.78[0.48,16.03]$ & 2006 & & & & \\
\hline Akin 2010 & 0 & 0 & 0 & 3 & & Not estimable & 2010 & & & & \\
\hline Kim 2013 & 3 & 15 & 6 & 22 & $21.3 \%$ & $0.67[0.14,3.22]$ & 2013 & & & & \\
\hline Onkendi 2014 & 2 & 5 & 6 & 27 & $13.1 \%$ & $2.33[0.31,17.35]$ & 2014 & & & & \\
\hline Borhani-Khomani 2016 & 2 & 34 & 0 & 23 & $5.6 \%$ & $3.62[0.17,78.85]$ & 2016 & & & & \\
\hline Ruvalcaba-Limon 2016 & 0 & 0 & 4 & 75 & & Not estimable & 2016 & & & & \\
\hline Choi 2018 & 18 & 116 & 0 & 8 & $6.3 \%$ & $3.19[0.18,57.74]$ & 2018 & & & & \\
\hline Li 2019 & 2 & 38 & 1 & 9 & $8.3 \%$ & $0.44[0.04,5.52]$ & 2019 & & & & \\
\hline Mitus 2019 & 0 & 12 & 17 & 135 & $6.4 \%$ & $0.27[0.02,4.78]$ & 2019 & & & & \\
\hline Lim 2021 & 0 & 31 & 0 & 3 & & Not estimable & 2021 & & & & \\
\hline Total $(95 \% \mathrm{CI})$ & & 273 & & 345 & $100.0 \%$ & $1.68[0.81,3.47]$ & & & & & \\
\hline Total events & 39 & & 44 & & & & & & & & \\
\hline \multicolumn{8}{|c|}{$\begin{array}{l}\text { Heterogeneity: } \mathrm{Tau}^{2}=0.00 ; \mathrm{Chi}^{2}=6.44, \mathrm{df}=8(\mathrm{P}=0.60) ; I^{2}=0 \% \\
\text { Test for overall effect: } \mathrm{Z}=1.39(\mathrm{P}=0.16)\end{array}$} & 0.01 & $0.1{ }^{1}$ & $\begin{array}{cc}10 \\
\text { Margin }<1 \mathrm{~cm}\end{array}$ & 100 \\
\hline
\end{tabular}

Figure S2 Forest plot showing the pooled odds ratios of local recurrence by surgical margin (margin $<1 \mathrm{~cm} v s$. margin $\geq 1 \mathrm{~cm}$ ) stratified by the phyllodes tumor grade.

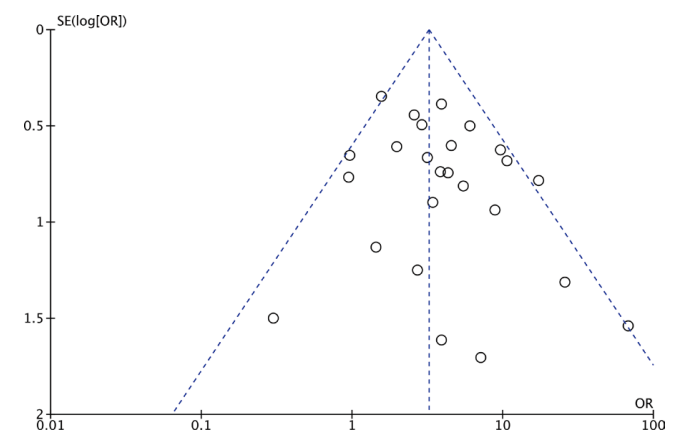

Figure S3 Forest plot showing the pooled odds ratios of local recurrence by surgical margin (margin $<1 \mathrm{~cm} v s$. margin $\geq 1 \mathrm{~cm}$ ) in borderline or malignant phyllodes tumor. 


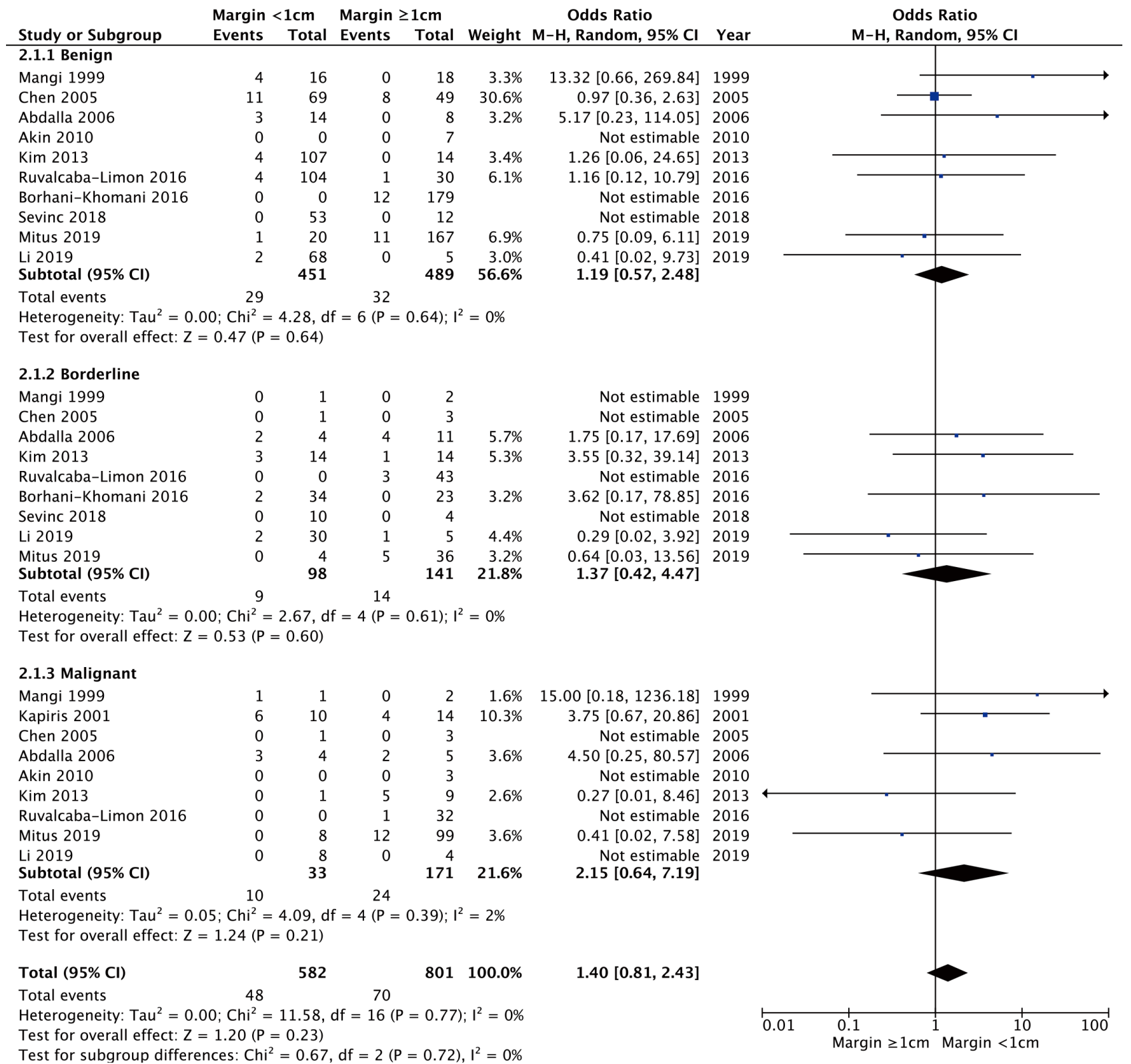

Figure S4 Funnel plot to assess the publication bias of the included studies in group of surgical margins (positive vs. negative).

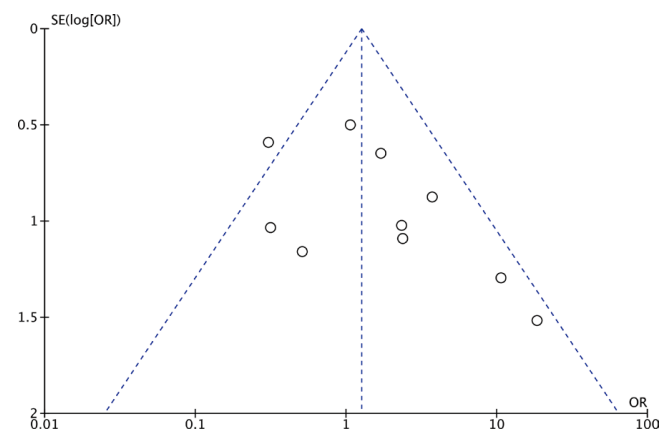

Figure S5 Funnel plot to assess the publication bias of the included studies in group of surgical margins (margin $<1 \mathrm{~cm} v s$. margin $\geq 1 \mathrm{~cm})$. 